\title{
FIP Guidelines for Dissolution Testing of Solid Oral Products Joint Report of the Section for Official Laboratories and Medicines Control Services and the Section of Industrial Pharmacists of the FIP
}

In 1981 FIP published Guidelines for Dissolution Testing of Solid Oral Products as a joint report of the Section for Official Laboratories and Medicines Control Services and the Section of Industrial Pharmacists. These guidelines were intended as suggestions primarily directed to compendial committees, working on the introduction of dissolution/release tests for the respective pharmacopoeias.

During the past 15 years there bave been many developments. Biopharmaceutics bas attracted much scientific as well as political interest. Dissolution test methodology bas been introduced to many pharmacopoeias and a number of regulations and guidelines on bioavailability, bioequivalence and in vitro dissolution testing bave been issued at national and international level.

The joint working group on dissolution of the two FIP sections therefore decided to establish a new dissolution guideline, taking all these developments into consideration but adding proposals for further barmonization and for definitions and procedures which are not yet covered by international recommendations.

FIP publisbed the "final draft" version in 1995 and co-sponsored an International Workshop in November 1996 to give colleagues from universities, drug autborities, pharmacopoeias and pharmaceutical industries the opportunity to contribute with their comments for furtber improvement of the guideline text prior to this publication of the final "official" version.

The following guideline is the resulting final "official" version and represents the position and policy of FIP on Dissolution as of December 1996.

\section{Introductory Remarks}

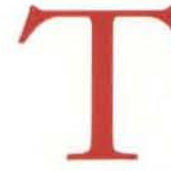

he first GUIDELINES FOR DISSOLUTION TESTING OF SOLID ORAL PRODUCTS were published in 1981 [1] as a joint report of the Section for Official Laboratories and Medicines Control Services and the Section of Industrial Pharmacists of the F.I.P. These Guidelines were intended as suggestions primarily directed to compendial committees, working on the introduction of dissolution/release tests for the respective Pharmacopoeias.

During the past decade, there have been many developments. Biopharmaceutics has attracted much interest scientifically as well as regarding drug regulatory policies. Dissolution test methodology has been introduced to many Pharmacopoeias and a number of regulations and guidelines on bioavailability, bioequivalence and in vitro dissolution testing have been issued at national and international levels.

These updated Guidelines (second edition) are the result of careful discussions of the joint working group of the two F.I.P. sections and are based on recent developments. Descriptions of test methodology are no longer necessary, because they are already published elsewhere, officially or semi-officially. Differences between the regulations of different countries and compendias were identified and proposals for harmonisation are made.
As far as is reasonable for the purpose of these Guidelines, technical terms and definitions have been adopted from other harmonised recommentions and mainly correspond to USP-terminology. New terms are "in vitro-in vivo comparison," "Verification" and "side batches." "In vitro-in vivo comparison" means any study collecting in vitro- and in vivo-data on the same set of test specimen to obtain information and understanding about how in vitro and in vivo performance are related to each other. A significant in vitro-in vivo correlation can be a result of an in vitro-in vivo comparison study, but valuable information could also be obtained when no correlation in a strict sense (e.g. USP levels) is achieved. "Verification" is used to define the in vivo data set which provides evidence that a chosen in vitro test method and the proposed limits are suitable for the drug formulation in terms of biopharmaceutical performance. "Verification" is proposed as a new terminus technicus to avoid the extension of "validation" on in vivo investigations. "Side batches" are batches of a given drug formulation which represent the intended upper and lower dissolution limits. They are preferrably to be derived from the defined manufacturing process by setting process parameters within the range of maximum variability expected from process validation studies. The term "dissolution" itself is used for all dosage forms,
The following guideline was elaborated by FIP with contributions from:

J. M. Aiache, Clermont Ferrant,

N. Aoyagi, Tokyo,

H. Blume, Escbborn,

J. Uressman, Frankfurt,

II. D. Friedel, Leverkusen,

L. I. Gratly, Rockville,

V. Gray, Rockville,

P. Helhne, Bronshoj,

B. Huthert, Rockville,

S. Kupp-Kubl, Geneva,

J. Krämer, Escbborn,

H. Kristensen, Copenhagen, f. Langentuehter, Basel,

L. Letsan, Montville,

L. Leskn, Rockville,

J. Limbery, Berlin,

I. Metilveray, Ottawa,

H. Möller, Frankfurt,

s. Oureshi, Ottrowa,

V. P. Stah, Rockville,

M. siewert, Frankfurt,

R. Silverkrïp, Bonn,

J. U. Walterssun, Uppsala,

I. Whiteman, Kansas City,

t. Wirbitzki, Frankfurt. 


\section{FIP Guidelines....cont.}

i.e. immediate-release (such as prompt drug releasing or conventional dosage forms) as well as modified-release products (such as controlled, delayed, extended, modified, prolonged or sustained).

\section{Concepts of Dissolution Testing}

In vitro dissolution testing serves as an important tool for characterising the biopharmaceutical quality of a product at different stages in its lifecycle. In early drug development in vitro dissolution properties are supportive for choosing between different alternative formulation candidates for further development and for evaluation of active ingredients/drug substances. In vitro dissolution data are supportive in the evaluation and interpretation of possible risks, especially in the case of controlled/modified-release dosage forms - e.g. as regards dose dumping, food effects on bioavailibility or interaction with other drugs, which influence gastrointestinal environmental conditions. Biopharmaceutical aspects are as important for stability concerns as they are for batch release after production, in vitro dissolution being of high relevance in quality control and quality assurance. Last but not least, in vitro dissolution data will be of great importance when assessing changes in production site, manufacturing process or formulation and assist in decisions concerning the need for bioavailability studies.

None of these purposes can be fulfilled by an in vitro test system without sufficient reliability. Reliability here would be defined as the system being experimentally sound, yielding precise, accurate, repeatable results and with sufficient knowledge of the in vivo relevance of the dissolution data obtained.

Requirements for dissolution testing have been reviewed in the literature [2 - 6]. Since in vitro dissolution is a physical test, defined by convention and is of a destructive nature, proving reliability requires special attention. It therefore is within the scope of these Guidelines to define suitable testing equipment and experimental design as well as to suggest the background for adequate physical and analytical validation, together with verification procedures according to the state of biopharmaceutical science.

The Guidelines are primarily dedicated to solid oral products. However, the general concepts may be adapted to in vitro dissolution testing of drug substances/powders, semi-solid oral products, suppositories and, with distinct restrictions, to other non-oral products.

\section{Apparatus}

Large numbers of different dissolution apparatuses are described in the literature, but only some of them withstand critical methodological examination.

Two basic technical principles are applied for in vitro dissolution testing: the "stirred beaker

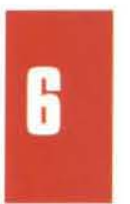
method" and the "flow through procedure." The "stirred beaker method" places the test specimen and a fixed volume of fluid in a large vessel, and stirring provides mechanical (hydrodynamic) agitation. This closed sys- tem design was adopted as first official method in USP XVIII in 1970, described as the rotating basket (apparatus 1, USP).

The rotating basket and the paddle (apparatus 2, USP) devices are simple, robust and adequately standardised apparatuses which are used all around the world and thus are supported by the widest experience of experimental use. It is because of these advantages that the paddle and rotating basket apparatuses are recommended in various guidelines as first choice for the in vitro dissolution testing of immediate as well as controlled/modified-release preparations.

However, because of the "single container" nature of the paddle/basket apparatus experimental difficulties may arise in terms of the need of a change in $\mathrm{pH}$ or of any other (partial) change in the test medium during an investigation. Furthermore, difficulties arise for a number of sparingly soluble drugs and for some dosage forms, particularly aerophilic multiple unit dosage forms that, tend to float initially. Proposals have been made to increase solubility by addition of an appropriate amount of surfactant.

With the flow-through cell (apparatus 4, USP) the specimen is placed in a small column which is continuously flushed with a stream of fluid, simultaneously providing the medium and the mechanical agitation for dissolution of the drug substance. It can be run as an open as well as a closed system. The open system design especially provides several advantages in some of the difficult cases mentioned above and was adopted first by the Deutscher Arzneimittelcodex (German Pharmaceutical Codex, DAC) in 1981.

The flow-through apparatus is currently monographed in USP, $\mathrm{Ph}$.Eur. and Ph.Jap. Description of the system is concordant worldwide. The paddle/basket system is described in USP, the European, the Japanese and many other Pharmacopoeias. Some minor discrepancies are still found in details of the respective monographs. Full

Table 1: Dissolution. Paddle and Basket Apparatus, Dimensions [mm] of the Vessel and the Paddle

\begin{tabular}{|c|c|c|c|c|}
\hline Item & EP III & $\begin{array}{l}\text { USP23 } \\
\text { (Suppl. 5) }\end{array}$ & JP XIII & Proposal \\
\hline \multicolumn{5}{|l|}{ Vessel } \\
\hline Height & $163 \pm 8$ & $160 \cdot 175$ & $160-175$ & $160-210$ \\
\hline Internal diameter & $102 \pm 4$ & $98-106$ & $98-106$ & $102 \pm 4$ \\
\hline \multicolumn{5}{|l|}{ Paddle } \\
\hline Shaft diameter & $9.75 \pm 0.35$ & $\begin{array}{l}9.4 \cdot 10.1 \\
\text { before coating }\end{array}$ & $9.4-10.1$ & $9.4 \cdot 10.1$ \\
\hline \multicolumn{5}{|l|}{ Blade } \\
\hline Upper chord & $74.0 \pm 0.5$ & $74.0-75.0$ & $74.0-75.0$ & $74.0 \pm 0.5$ \\
\hline Lower chord & $42.0 \pm 1$ & $42.0 \pm 1.0$ & 42.0 & $42.0+1.0$ \\
\hline Height & $19.0 \pm 1$ & $19.0 \pm 0.5$ & $19.0 \pm 0.5$ & $19.0 \pm 0.5$ \\
\hline Radius (disk) & 41.5 & $41.5 \pm 1.0$ & 41.5 & $41.5 \pm 1.0$ \\
\hline Radius (upper corners) & 1.2 & 1.2 & 1.2 & 1.2 \\
\hline Thickness & $4.0 \pm 1$ & $4.0 \pm 1.0$ & $4.0 \pm 1.0$ & $4.0 \pm 1.0$ \\
\hline \multicolumn{5}{|l|}{ Positioning of the stirring device } \\
\hline Distance from the bottom & $25 \pm 2$ & $25 \pm 2$ & $25 \pm 2$ & $25 \pm 2$ \\
\hline and vertical axis of the vessel & $\leq 2$ & $\leq 2$ & $\leq 2$ & $\leq 2$ \\
\hline Stirring characteristics & $\begin{array}{l}\text { Smoothly } \\
\text { without } \\
\text { significant } \\
\text { wobble }\end{array}$ & $\begin{array}{l}\text { Smoothly } \\
\text { without } \\
\text { significant } \\
\text { wobble }\end{array}$ & No comment & $\begin{array}{l}\text { Smoothly } \\
\text { without } \\
\text { significant } \\
\text { wobble } \\
(\leq 0.5 \mathrm{~mm})\end{array}$ \\
\hline
\end{tabular}


Table 2: Dissolution. Paddle and Basket Apparatus, Dimensions [mm] of the Basket.

\begin{tabular}{|c|c|c|c|c|}
\hline Item & EP III & $\begin{array}{l}\text { USP23 } \\
\text { (Suppl. 5) }\end{array}$ & $J P X I I I$ & Proposal \\
\hline $\begin{array}{l}\text { Basket } \\
\text { Shaft diameter }\end{array}$ & $\begin{array}{l}(9.75 \pm 0.35) \\
6.4 \pm 0.1\end{array}$ & $\begin{array}{l}6.3-6.5 \text { or } \\
9.4-10.1\end{array}$ & $\begin{array}{l}9.75-0.35 \text { or } \\
6.4 \pm 0.1\end{array}$ & $\begin{array}{l}9.4-10.1 \\
\text { (corres. to shaft dia. } \\
\text { of the paddle) }\end{array}$ \\
\hline $\begin{array}{l}\text { Screen } \\
\text { Wire thickness } \\
\text { Openings } \\
\text { Height of screen } \\
\text { Total height of basket } \\
\text { Internal dia. of basket } \\
\text { External dia. of basket } \\
\text { External dia. of ring } \\
\text { Vent hole diamenter } \\
\text { Height of coupling disk }\end{array}$ & $\begin{array}{l}0.245 \\
0.381 \\
27.0 \pm 1 \\
36.8 \pm 3 \\
20.2 \pm 1 \\
22.2 \pm 1 \\
25.4 \pm 3 \\
2 \\
5.1 \pm 0.5\end{array}$ & $\begin{array}{l}0.254 \text { or } 0.406 \\
0.381 \text { or } 0.864 \\
27.0 \pm 1.0 \\
36.8 \pm 3.0 \\
20.2 \pm 1.0 \\
22.2 \pm 1.0 \\
25.4 \pm 3 \\
2 \\
5.1 \pm 0.5\end{array}$ & $\begin{array}{l}N^{\circ} 36 \text { sieve } \\
0.425 \\
27.0 \pm 1 \\
36.8 \pm 3 \\
20.2 \pm 1 \\
22.2 \pm 1 \\
25.4 \pm 3 \\
2 \\
5.1 \pm 0.5\end{array}$ & $\begin{array}{l}0.25^{17} \\
0.400^{11} \\
27.0 \pm 1.0 \\
37.0 \pm 3.0 \\
20.0 \pm 1.0 \\
22.0 \pm 1.0 \\
25.0 \pm 3.0 \\
2.0 \pm 0.5 \\
5.0 \pm 0.5\end{array}$ \\
\hline $\begin{array}{l}\text { Positioning of the stirring } \\
\text { device } \\
\text { Distance from the bottom } \\
\text { Distance between shaft axis } \\
\text { and vertical axis of the vessel }\end{array}$ & $\begin{array}{l}25 \pm 2 \\
\leq 2\end{array}$ & $\begin{array}{l}25 \pm 2 \\
\leq 2\end{array}$ & $\begin{array}{l}25 \pm 2 \\
\leq 2\end{array}$ & $\begin{array}{l}25 \pm 2 \\
\leq 2\end{array}$ \\
\hline Stirring characteristics & $\begin{array}{l}\text { Smoothly } \\
\text { without } \\
\text { significant } \\
\text { wobble }\end{array}$ & $\begin{array}{l}\text { Smoothly } \\
\text { without } \\
\text { significant } \\
\text { wobble } \\
\text { (max. runout } \\
\pm 1 \mathrm{~mm} \text { ) }\end{array}$ & No comment & $\begin{array}{l}\text { Smoothly } \\
\text { without } \\
\text { significant } \\
\text { wobble } \\
\text { (max. runout } \\
\text { at the basis of } \\
\text { the basket } \\
\pm 1 \mathrm{~mm} \text { ) }\end{array}$ \\
\hline
\end{tabular}

1) Test sieve (40 mesh) according to DIN ISO-Norm 3310 (Part 1): 1990 (dimensions relevant for the plain wire cloth) international harmonisation is strongly recommended as proposed in Tables 1 and 2.

Another system (apparatus 3) USP describes the reciprocating cylinder. With these four apparatuses, dissolution testing of most oral drug products should be possible on a reasonable basis. Neither too tight restrictions nor unnecessary proliferation of alternative dissolution apparatuses should be encouraged. If an individual drug product cannot be accomodated by one of the apparatuses, described above, alternative models or appropriate modifications have to be developed. However, in such a case superiority of the alternative or the modification has to be proven in comparison to the well established and standardised apparatuses. In the past, many papers intended to justify an alternative model by proving that in vitro dissolution results were equivalent or similar to those obtained with e.g. the paddle method. According to the understanding of these

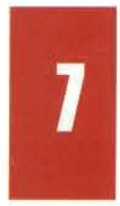




\section{FIP Guidelines....tont.}

Guidelines, the latter provides clear evidence that the paddle method should be used!

Modification of the apparatus as described in the Pharmacopoeias or the harmonisation proposals in Tables 1 and 2 can be intended for automation e.g. of sampling procedure. In such cases, which could potentially have an influence on agitation characteristics [7], or any other measure, it should be validated on a product-by-product basis that results are equivalent with and without the modification.

\section{Experimental Testing Conditions}

For all applications, in vitro dissolution data should at least allow some interpretation with regard to in vivo biopharmaceutical performance. In order to increase their predictive value, attempts have been made to adjust in vitro test conditions [8 - 11] as close as possible to physiologic conditions. Nevertheless, several examples demonstrate that such conditions can also lead to misinterpretations and are not able to guarantee in vitro results routinely relevant to the in vivo situation [12].

In general, an aqueous medium should be used. It is not recommended to attempt to strictly mimic the physiologic gastrointestinal environment (e.g. composition of gastric or intestinal fluid) but to choose the testing conditions as far as is reasonable, based on the physico-chemical characteristics of drug substance, within the range which a drug or dosage form could experience after oral administration. These following ranges were established based on several conferences and recommendations [e. g. 13 15]. There might be specific products for which no dissolution test can be established without exceeding the recommended ranges of testing conditions. In these cases, it should be clearly demonstrated that dissolution results obtained with other, more extreme testing conditions (e.g. $\mathrm{pH}>8.0$ ) allow for appropriate biopharmaceutical interpretation.

For basket/paddle methods the volume should be 500 to $1000 \mathrm{ml}$. $900 \mathrm{ml}$ had been introduced historically; $1000 \mathrm{ml}$ should be easier to handle in a metric system, this volume being practicable with all equipment commercially available today. $1000 \mathrm{ml}$ therefore should be considered for new drug products or in case of a revision of existing test procedures. This recommendation does not mean that $1000 \mathrm{ml}$ should be adopted to all existing test procedures and specifications. Although larger vessels, such as up to $4,000 \mathrm{ml}$, could be advantageous for poorly soluble drugs, they are not described in compendia, and thus are not as well standardised and therefore should be regarded as modification of a compendial method (see section 2.)

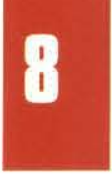

The $\mathrm{pH}$ of the test medium should be set within $\mathrm{pH} 1$ and 6.8. A higher $\mathrm{pH}$ needs to be justified on a case-by-case basis and in general should not exceed $\mathrm{pH} 8$. For low $\mathrm{pH}$ in the acidic range $\mathrm{HCl}$ should be used $(0.1 \mathrm{~N} \mathrm{HCl}$ for $\mathrm{pH} 1)$. If, in a certain case, artificial gastric juice without enzymes ( $\mathrm{pH}$ 1.2) is advantageous, this should be demonstrated. The use of simulated gastric juice (with pepsin) may be appropriate for gelatine capsules.

In the $\mathrm{pH}$-range of 4.5 to 8.0 USP buffer solutions are recommended, as summarized in Table 3 . A change of $\mathrm{pH}$ of dissolution

\section{Table 3: Proposed Dissolution Media}

\begin{tabular}{ll}
\hline $\begin{array}{l}\text { Simulated intestinal fluid } \\
\text { without pancreatin pH 7.5 }\end{array}$ & $\begin{array}{l}250 \mathrm{ml} \text { of a solution containing } 6.8 \mathrm{~g} \text { monobasic potassium phosphate } \\
+\end{array}$ \\
& + water to make $1000 \mathrm{ml}$
\end{tabular}

+ water to make $1000 \mathrm{ml}$

Proposed Composition

$3.636 \mathrm{~g}$ of $\mathrm{HCl}$, corresponding to $8.3 \mathrm{ml}$ hydrochloric acid $37 \%(\mathrm{~m} / \mathrm{m})$ per $1000 \mathrm{ml}$ of aqueous solution

Acetate buffer solution $\mathrm{pH} 4.5$ :

$2.99 \mathrm{~g}$ of sodium acetate trihydrate and $1.66 \mathrm{~g}$ of glacial acetic acid are dissolved in water to $1000 \mathrm{ml}$

Phosphate buffer solution $\mathrm{pH} 4.5$ :

$13.61 \mathrm{~g}$ monobasic potassium phosphate are dissolved in $750 \mathrm{ml}$ of water. After adjusting the $\mathrm{pH}$ to 4.5 with $0.1 \mathrm{~N}$ hydrochloric acid or $0.1 \mathrm{~N}$ sodium hydroxide, water is added to make $1000 \mathrm{ml}$

50 volumes of $0.2 \mathrm{M}$ monobasic potassium phosphate solution

+ specified volume of $0.1 \mathrm{~N}$ sodium hydroxide

+ water to 200 volumes

DissolutionTechnologies/NOVEMBER 1997

medium during the test or a $\mathrm{pH}$ gradient may be appropriate for gastroresistent formulations and products for which dissolution testing at one $\mathrm{pH}$-level or at different $\mathrm{pH}$-levels in parallel does not give biopharmaceutically relevant results.

The use of water as dissolution medium bears the disadvantage that test condition details, such as $\mathrm{pH}$ and surface tension, can vary depending on the source of water and may be changed during the dissolution test itself, due to the influence of the drug product and to the (re)absorption of carbon dioxide from air. Water therefore is recommended as dissolution medium only when it is proven, that the variations mentioned do not have influence on the dissolution characteristics.

Further additives e.g. enzymes, salts or surfactants, could be considered in specific cases. Their use should be justified as regards nature and concentration of additive [16]. Addition of organic solvents should be avoided.

Agitation typically should be obtained in the basket/paddle apparatus by stirring at 50 to $100 \mathrm{rpm}$ and in general should not exceed 150 rpm. Although maximum discriminatory power should be obtained with lowest stirring rate, in many cases experience with $75 \mathrm{rpm}$ was felt to represent a reliable agitation for paddle equipment [17].

Regarding media temperature, $37 \pm 0.5^{\circ} \mathrm{C}$ should generally be 
used for oral dosage forms. Slightly increased test temperatures (e.g. (e.g. $38 \pm 0.5^{\circ} \mathrm{C}$ ) are under consideration for special applications e.g. for rectal dosage forms, lower temperatures (e.g. $32 \pm 0.5^{\circ} \mathrm{C}$ ) for transdermal systems.

Relevant parameters to be considered for the definition of test conditions are solubility and deaeration. In former Guidelines [1], "sink" conditions were requested. "Sink" was defined in different ways e.g. as 10 to $20 \%$ [1] or approximately $30 \%$ [18] of solubility concentration to assure that dissolution is not significantly influenced by solubility characteristics. Since "sink" conditions per se do not guarantee in vivo-in vitro associations and since reliable and predictive in vitro profiles in certain cases can be obtained by violating "sink" conditions, solubility and drug substance concentrations during the test should be matter of verification studies to demonstrate that a chosen in vitro test method yields biopharmaceutically relevant results.

Case-by-case validation is also required regarding deaeration since some formulations will be sensitive whereas others are robust in this concern, thus making deaeration unnecessary. The deaeration method has to be clearly characterised, since the method chosen can have impact on dissolution profiles [19]. It is noted that the flow rate in the flow-through cell (open circuit) is particularly sensitive to the presence of air in the medium.

$\mathrm{Ph}$.Jap. is currently the only Pharmacopoeia that requires a specific (very solid) sinker device for all capsule formulations. USP recommends a few turns of wire helix when specimen tend to float. EFPIA harmonisation proposal suggests a similar one. Sinkers can significantly influence the in vitro dissolution profile of a drug [20]. Since they are used especially with formulations causing problems during test performance, e.g. flotation, they will alter the dissolution profile, so that other recommendations [18] are not applicable.

The use of sinkers therefore has to be part of case-by-case dissolution validation as well as of in vitro-in vivo comparison studies. Any strict requirement on use of sinkers or specific sinker types lacks scientific justification.

\section{Qualification and Validation}

Due to the nature of the test method, quality by design is an important qualification aspect for in vitro dissolution test equipment. Besides the geometrical and dimensional accuracy and precision as described and commented in section 2 (including Tables 1 and 2), any irregularities such as vibration or undesired agitation by mechanical imperfection are to be avoided.

Besides the specification of the apparatus, qualification of dissolution equipment has to consider critical parameters, e.g. temperature of test medium, rotation speed/flow rate, volume, sampling probes and procedures, to be monitored periodically during the periods of use.

Apparatus suitability test is a further important aspect of qualification and validation. The use of USP calibrator tablets (disintegrating as well as non-disintegrating) has been controversial for some time. However, it is the only standardised approach and has been helpful to identify system or operator failures. Since some individual drug products might reveal similar or even higher sensitivity against technical variance in comparison to USP calibrator tablets, "in-house" standards are judged acceptable as additional, or, if validated, equivalent for calibrator tablets.

The suitability test has to cover each individual apparatus. Paddle and basket equipment, as well as $12 \mathrm{~mm}$ and $22.6 \mathrm{~mm}$ flow-through cells have to be qualified, unless only paddle or basket, or in the case of flow-through cells only small or large cell is used in one specific piece of equipment. The system suitability test of USP Apparatus must be performed with both a multiparticulate and a monoparticulate standard formulation. A system suitability test for flow-through cells has just been established and will be soon published [22].

Apparatus suitability tests are recommended to be performed not less than twice per year per equipment and after any equipment change, significant repair or movement. However, a switching between paddle and basket, when the apparatus has been calibrated for both, should not require recalibration.

Additional validation aspects are precise product related operation instructions (e.g. deaeration procedure). Dissolution results may be influenced by the physical behaviour of the specimen such as floating, adherence to the walls, etc. Thus, critical inspection and observation of test performance during the test procedure is required. This approach is especially important to explain any "out-lying" results and it clearly limits the extent of automation for a number of drug formulations.

Validation of automated systems, either concerning the sampling and analytical part or also including media preparation and test performance, has to consider accuracy, precision and avoid contamination by any dilutions, transfers, cleaning or sample or solvent preparation procedures. There should be proof that there is no interference. This shall be evidence of no significant differences between data obtained with the manual dissolution equipment (see section 2) and the automated system, including manipulations such as permanent sampling probes, additional valves, hollow shafts, etc. Since sensitivity to such modification may be formulation related, qualification and validation of automated dissolution equipment and testing has to be established on a case-by-case basis.

Validation of the analytical procedures applied in dissolution testing, either automated or conventional, has to comply with "Validation of Analytical Procedures" (ICH) and "Validation of Compendial Methods" ( $<1225\rangle$, USP). Validation aspects thus are accuracy, precision (repeatability, reproducibility), specificity, linearity, range. Special care has to be taken regarding stability of the drug in test medium and sample solutions, since the test procedure often includes exposure to hydrolytic media at $37^{\circ} \mathrm{C}$ over significant time spans.

\section{Formulation Characterisation}

During development of the drug formulation, as a basis for any in vitro-in vivo comparison study as well as for the final choice of test conditions for quality control

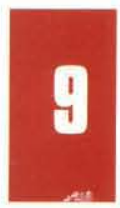




\section{FIP Guidelines....cont.}

purposes, the respective dosage form has to be thoroughly characterised in vitro with respect to its biopharmaceutical performance. Special attention has to be paid to controlled/modified-release preparations, since sufficient information has to be gained about how much the dosage form itself, rather than variations in test conditions, "control" the rate of drug release.

Therefore, extensive dissolution tests are necessary to understand the delivery system and to have a rationale for the design of e.g. an in vitro-in vivo comparison study. The in vitro test profile will preferably consist of numerous individual dissolution tests under many different test conditions, involving the $\mathrm{pH}$ of test media and agitation within the ranges given in section 3 . Variation of ionic strength, surfactants, enzymes or apparatus should be evaluated, if an influence on dissolution is expected for the individual formulation.

For formulation characterisation, dissolution tests should be performed under the different test conditions until actual dissolution (e.g. mean of six specimen) exceeds $80 \%$ of labelled amount. When, even with test prolongation, results remain significantly below $80 \%$ and solubility is not the limiting parameter, recovery control should be performed to prevent misinterpretation of dissolution data.

Most in vitro characteristics can be related to physiological parameters, such as $\mathrm{pH}$-profile of test media (gastric and intestinal $\mathrm{pH}$ ), stirring or flow rate (gastrointestinal motility, shearing forces), addition of lipids, enzymes, surfactants (to simulate the physiological environment). Thus, the information from formulation characterisation in vitro can be used later as a tool to demonstrate the reliability of an in vitro-in vivo comparison, based on a distinct in vitro model, as well as for interpretation of all those examples where no or only a poor correlation of in vitro and in vivo data can be achieved. However, it is obvious that a meaningful in vitro-in vivo comparison (see section 6) is the more probable, the less affected in vitro dissolution of a given drug formulation is by changes in the environmental test conditions.

\section{In vitro-in vivo Comparison}

An in vitro test system for a given drug formulation serves as the tool as which it is designated only, if it can distinguish between "good" and "bad" batches. "Good" here means "of acceptable and reproducible biopharmaceutical performance in vivo". Thus in vivo relevance of an in vitro test system is sought. The purpose of in vitroin vivo comparison studies in this sense is the scientific verification of the in vitro test system and the respective specification limits for a given drug formulation.

Regarding extended-release dosage forms the USP [18] has categorised correlative methods, harmonised in a wide international consensus, as correlation level A (1:1 relationship between in vitro and in vivo dissolution, calculated by numerical deconvolution [23, 24], according to Wagner-Nelson method [25] or to Loo-Riegelmann method [26]), correlation level B (statistical moment analysis [27, 28]) and correlation level C (single-point correlation of a dissolution time vs. a pharmacokinetic parameter). Depending on the correlation level finally obtained, in vitro dissolution properties will be decisive for the necessity of how many batches should be included for a correlation study, e.g. for establishment of in vitro dissolution specification limits. According to recent recommendations, one single batch may be sufficient for a scientifically and formally acceptable correlation $[15,18]$, only in case of a correlation level $\mathrm{A}$ and a product with a drug release, completely independent from environmental conditions, which then is represented by only one dissolution curve. Scientific and pragmatic approaches for level A correlations have been proposed [29]. In case of a level A correlation, manufacturing site changes, process and equipment changes, minor formulation modifications, scale-up considerations and specification of dissolution limits can be based and justified without further in vivo-studies.

In all other cases at least two or three different batches have to be used, offering differences in their biopharmaceutical properties, sufficient for correlation purposes. Nevertheless, these differences have to be 'effected' by only small modifications of manufacturing variables within the ranges of the given process. In cases where differences cannot be achieved by these variations of the production process, major changes will be required to obtain samples for in vitro-in vivo comparison. However, any correlation received for different formulations bears the risk of being somewhat arbitrary. A final evaluation of type and influence of the changes in the manufacturing processes requires thorough in vitro dissolution tests ('biopharmaceutical profile'; see section 5) prior to an administration to human volunteers in a clinical study.

Concerning modified-release products there is international consensus that levels $\mathrm{A}$ to $\mathrm{C}$, with a quality ranking $\mathrm{A}>\mathrm{B}>\mathrm{C}$, are acceptable for correlation e.g. for specifications of dissolution limits. A

\section{Table 4: Possible reasons for poor in vivo-in vitro correlations}

\section{Fundamentals}

- in vivo dissolution is not the rate limiting step for drug absorption

- no in vitro test is able to model in vivo dissolution

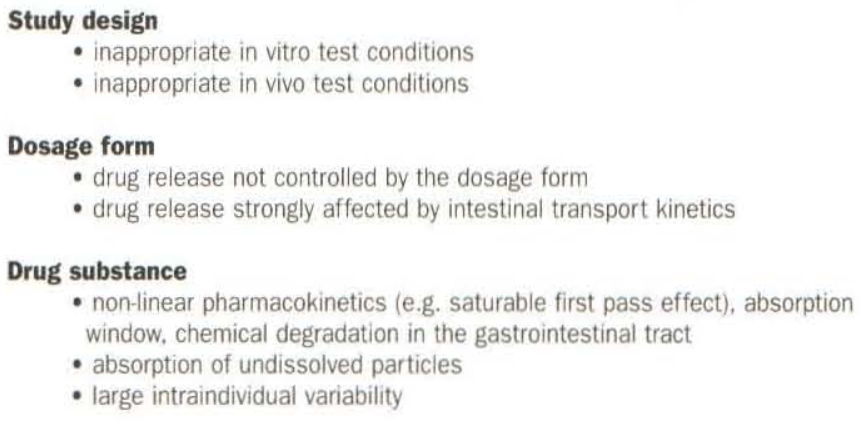

number of different reasons (see Table 4) could be responsible for "poor" or no correlation.

Even with highly sophisticated techniques it is often difficult to obtain meaningful in vitro-in vivo comparisons, especially for biopharmaceutically very similar (bioequivalent?) products, such as batches of one drug formulation, representing the upper and the lower dissolution limits. 
Recently, proposals have been made [30] which in vitro-in vivo comparison results scientifically and formally could suffice as verification of dissolution specification of controlled/modified-release products. In case of a significant quantitative correlation, dissolution limits can be derived by interpolation, when batches outside the specified biopharmaceutical range are tested for in vitro-in vivo comparison. Then, at least three batches should be tested in vitro and in vivo. A qualitative, i. e. rank-order correlation verifies ranges, when at least three batches are tested in vivo and in vitro and the dissolution data of two of the experimentally investigated batches are concluded bioequivalent and their dissolution characteristics are specified as upper and lower dissolution limits (Fig. 1).

Where no correlation is obtained from an in vitro-in vivo comparison study, an alternative approach (Fig. 2) could consist of demonstrating bioequivalence of the proposed formulation to formulations with dissolution profiles at the upper and lower limits of the specification [13].

The number of volunteers to be included in such comparative bioavailability studies or in an in vitro-in vivo comparison study is to be defined on a case-by-case basis but in general should not be less than twelve.

The batch size of a formulation for in vitro-in vivo comparison studies need not be of full production scale. Parameters for manufacture of these batches, especially of formulations representing the intended dissolution limits, should be defined from process validation

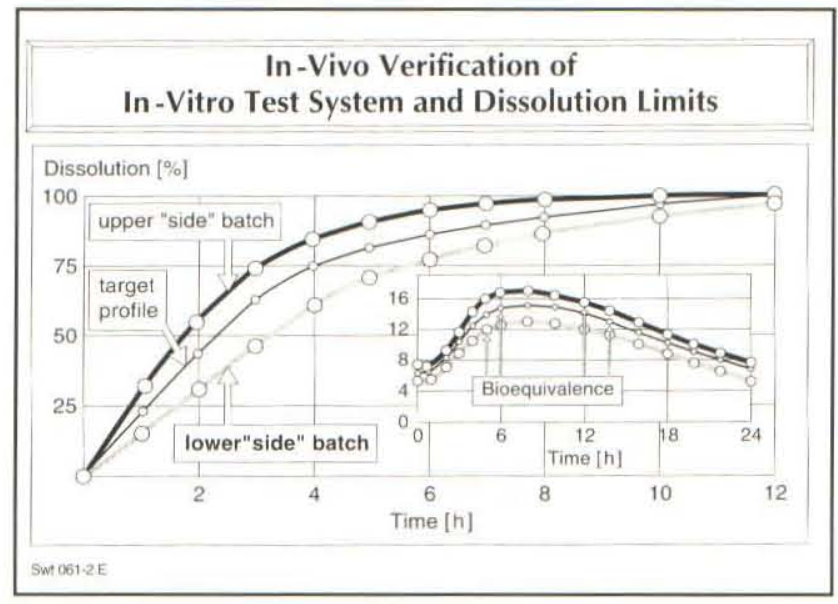

Figure 1

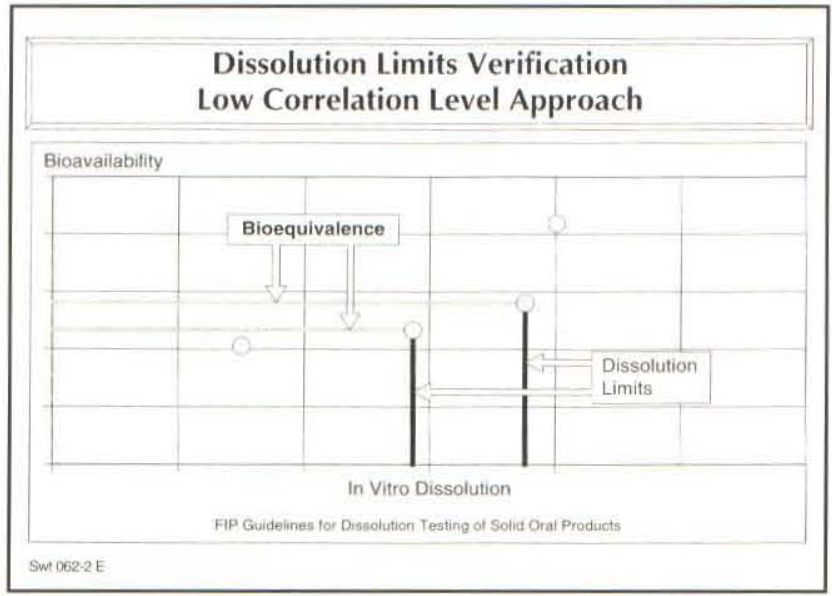

Figure 2

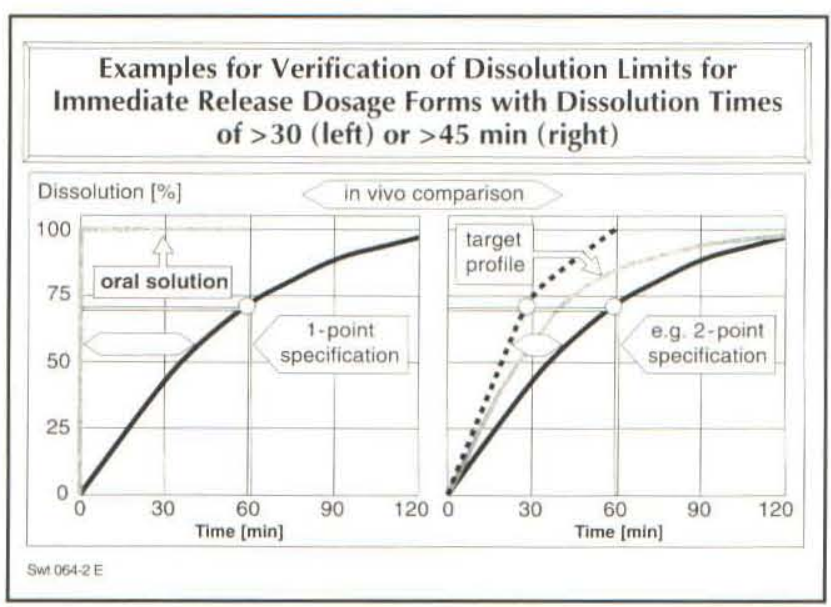

Figure 3 studies according to the expected maximum variability of process parameters ("side batches").

Concerning immediate/conventional-release dosage forms a suitable design for an in vitro-in vivo comparison study could consist of a two-way crossover between an oral solution and a formulation representing the (lower) specified dissolution limit. (Fig. 3).

\section{Dissolution Limits}

The purpose of specifying dissolution limits is to ensure batchto-batch consistency within a range which guarantees acceptable biopharmaceutical performance in vivo. Limits therefore have to be defined based on experience gained during the drug development stage especially regarding clinical development and/or bioequivalence studies. In most cases deduction of limits requires thorough in vitro-in vivo comparison studies as described in section 6.

For immediate/conventionalrelease formulations typically one limit is specified to ensure that most of the active ingredient is released within the present time period. Regarding the deduction of limits, different procedures are recommended, depending on the individual dissolution characteristics. However, it is clearly stated, that the following categorisation only concerns the specification verification process. It does not qualify or disqualify drug formulations with dissolution properties, characterised by a specified time of $>15$ minutes.

In case of very fast drug release, single point dissolution data during the development period and a single point specification, consisting of a parameter quantitating the extent and a parameter to define the time, are judged sufficient. A formulation is in this concern understood as very fast releasing, when at least $80 \%$ of the drug substance, corresponding to "Q" = 75\% (see Table $5 \mathrm{a}$ in section 8 ), is dissolved in about 20 - 30 minutes (including any lag times due to dissolution of a tablet coating or capsules) under reasonable and justified test conditions. In this case dissolution limits

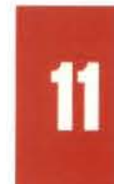




\section{FIP Guidelines....Eont.}

can be defined based on in vitro data, obtained during drug development without an in vitro-in vivo comparison study.

Although in vitro- and in vivo-time axes need not be related in a 1:1 ratio, the suggested dissolution time window corresponds to typical gastric emptying times [31-33].

Immediate/conventional-release formulations with a specified dissolution time of more than 30 minutes will require an in vitro-in vivo comparison study and dissolution profiles with several (e. g. 3) points, obtained during development, to specify single point limits. Formulations with a specified dissolution time of $>45$ minutes may require two specified dissolution times for quality control purposes.

Gastro-resistant drug products should be treated like immediate-release products for the purpose of specifying limits for the second dissolution test period, following the initial acidic test phase.

For modified-release formulations (except delayedrelease) dissolution requirements should consist of at least three points. The first limit is specified to prevent "dose dumping" and therefore should be set after a testing interval of one to two hours or corresponding to a dissolved amount of 20 $30 \%$ of labelled drug substance. The second limit should define the dissolution pattern and thus be set around $50 \%$ release of labelled drug substance. The final limit is specificated to ensure (almost) quantitative

\begin{tabular}{|c|c|}
\hline 5a: Imn & 1ediate/conver \\
\hline Stage & Number Tested \\
\hline $\mathrm{S}_{1}$ & 6 \\
\hline $\mathrm{S}_{2}$ & 6 \\
\hline $\mathrm{S}_{3}$ & 12 \\
\hline
\end{tabular}

\section{5b: Modified (Extended-Release) Drug Products}

Stage Number Tested Acceptance Criteria

$\begin{array}{lll}L_{1} & 6 & \text { No individual value lies outside each of the stated ranges }\end{array}$ and no individual value is less than the stated amount at

$\mathrm{L}_{2} \quad 6$ the final test time

The average value of the 12 units $\left(L_{1}+L_{2}\right)$ lies within each of the stated ranges and is not less than the stated amount at the final test time; none is more than $10 \%$ of labelled content outside each of the stated ranges; and none is more than $10 \%$ of labelled content below the stated amount at the final test time

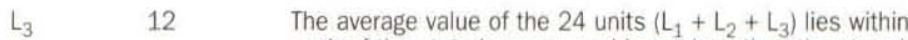
each of the stated ranges, and is not less than the stated amount at the final test time; not more than 2 of the 24 units are more than $10 \%$ of labelled content outside each of the stated ranges; not more than 2 of the 24 units are more than $10 \%$ of labelled content below the stated amount at the final test time; and none of the units is more than $20 \%$ of labelled content outside each of the stated ranges or more than $20 \%$ of labelled content below the stated amount the final test time

\section{5c: Gastro Resistant (Delayed-Release) Drug Products}

\section{Acidic stage}

\section{Stage Number Tested Acceptance Criteria}

$A_{1} \quad 6 \quad$ No individual value exceeds $10 \%$ dissolved

$\mathrm{A}_{2} \quad 6$

A $\quad 12$

Average of 12 units $\left(A_{1}+A_{2}\right)$ is not more than $10 \%$ dissolved, and no individual unit is greater than $25 \%$ dissolved

Average of the 24 units $\left(A_{1}+A_{2}+A_{3}\right)$ is not more than $10 \%$ dissolved, and no individual unit is greater than $25 \%$ dissolved

\begin{tabular}{cc}
\multicolumn{2}{c}{ Buffer stage } \\
Stage & Number Tested \\
$\mathrm{B}_{1}$ & 6 \\
$\mathrm{~B}_{2}$ & 6 \\
$\mathrm{~B}_{3}$ & 12
\end{tabular}

\section{Acceptance Criteria}

Each unit is not less than $\mathrm{Q}+5 \%$

Average of 12 units $\left(B_{1}+B_{2}\right)$ is equal to or greater than $\mathrm{Q}$, and no unit is less than Q - $15 \%$

Average of the units $\left(B_{1}+B_{2}+B_{3}\right)$ is equal to or greater than Q, not more than 2 units are less than Q - $15 \%$, and no unit is less than Q - $25 \%$ drug release, which is generally understood as $\geq 80 \%$. The dissolution run in quality control therefore should be extended for the time interval until at least $80 \%$ of drug substance is dissolved. Shorter test intervals can be acceptable in special cases but require justification on the basis of (delayed-release) products (Table 5). The approach with a maximum of three stages and individual units tested for deviation from stated ranges corresponds well to requirements for content uniformity. Although there is preference in common practice in pharmaceutical industries to decide upon batch release not later than stage 2, the three 
step approach is the best solution for formal specifications, especially when referring to end-of-shelf life specification. Reference to labelled content does not apply for products with intentional different content at time of manufacturing, such as in cases of stability overage.

\section{Special Applications}

A specific value of dissolution testing is recognized in its applications in scale-up and manufacturing changes for immediate/conventional-release and modified-release oral products. The AAPS/FDA/USP Scale-up workshops [34, 35] recommend certain types and ranges of changes for which the sameness of in vivo product performance is assumed, based on in vitro dissolution data. In addition, the Scale-Up and Post-Approval Change (SUPAC) document of FDA [36] defines the level of changes with respect to components and composition, site of manufacturing, the scale of manufacturing, and process and equipment changes in manufacturing for an immediate-release oral formulation. Depending on the level of change, different levels of dissolution testing are recommended to assure continuing product quality and performance characteristics. Respectively, the documentation needed to assure the product performance varies, depending on thera-

\section{Table B: Dissolution media that may reflect gastric conditions [fasted: SGF] and conditions in small intestine [fasted: Fassif; fed: FeSsIf]}

\begin{tabular}{|c|c|c|c|}
\hline & $\begin{array}{l}2.5 \mathrm{G} \\
2.0 \mathrm{G} \\
\text { qs. } 1000 \mathrm{ml}\end{array}$ & $\begin{array}{l}\text { FaSSIF } \\
\mathrm{KH} 2 \mathrm{PO} 4 \\
\mathrm{NaOH} \\
\text { NaTaurocholate } \\
\text { Lecithin } \\
\mathrm{KCl} \\
\text { Distilled Water }\end{array}$ & $\begin{array}{l}0.029 \mathrm{M} \\
\text { q.s pH } 6.8 \\
5 \mathrm{mM} \\
1.5 \mathrm{mM} \\
0.22 \mathrm{M} \\
\text { q.s. } 1000 \mathrm{ml}\end{array}$ \\
\hline $\begin{array}{l}\text { SGF } \\
\mathrm{HCl} 0.01-0.05 \mathrm{~N} \\
\text { Sodium lauryl sulfate } \\
\text { Sodium Chloride } \\
\text { Distilled Water }\end{array}$ & & $\begin{array}{l}\text { FeSSIF } \\
\text { Acetic acid } \\
\mathrm{NaOH} \\
\text { NaTaurocholate } \\
\text { Lecithin } \\
\mathrm{KCl} \\
\text { Distilled Water }\end{array}$ & $\begin{array}{l}0.144 \mathrm{M} \\
\text { q.s. } \mathrm{pH} 5 \\
15 \mathrm{mM} \\
4 \mathrm{mM} \\
0.19 \mathrm{M} \\
\text { q.s. } 1000 \mathrm{ml}\end{array}$ \\
\hline
\end{tabular}

[45]. Special tests have also been suggested for consideration of specific situations, such as achlorhydric elderly patients [46].

\section{Conclusions}

In many international discussions, mainly over the years 1988 to 1993, consensus was reached on some essential aspects, to which these Guidelines refer. On the other hand, many aspects have either not yet been sufficiently explored or have not been harmonised. In these cases, e.g. more precise specifications of dissolution media and proposals for in vitro-in vivo comparison approaches and verification of specifications for immediate/conventional-release, delayed-release and modified-release preparations, the revised Guidelines will provide contributions for reasonable standardization, while acknowledging that for a number of drugs e.g. with special physico-chemical or pharmacokinetic properties, case-by case development is required.

These Guidelines should be helpful and applicable for all involved in in vitro dissolution testing. However, there was special emphasis on providing reliable guidance for industrial research and development, process validation and quality control, making the Guidelines especially applicable for industry, drug authorities and control laboratories peutic range, solubility and permeability factors of the drug. For changes greater than the acceptable values in the scale-up workshop report, additional dissolution profile determinations in several media are recommended for immediate-release products.

For major changes, that are likely to have a significant impact on formulation quality and performance, an in vivo bioequivalence study is recommended in addition to extensive dissolution profile testing. For manufacturing site change, scale-up, equipment changes and minor process changes dissolution testing is deemed sufficient to assure product quality and performance.

In vitro dissolution tests have also been used to try to simulate food-effects on bioavailability. So far, these different attempts [37 43] have had extremely limited success in prediction [44]. Assuming that gastro-intestinal transit times are significantly contributing to potential food-effects on bioavailability, the value of an in vitro model for food-effects will be limited to an evaluation whether direct drugfood-interaction could be of relevance for the observed changes in bioavailability in the in vivo study.

Test media that may reflect gastric conditions (fasted) and intestinal conditions (fasted/fed) and thus may give additional information for research and development purpose are summarised in Table 6 but also for universities, hospitals, pharmacies or others, when involved in (bio)pharmaceutical quality evaluation.

In general these Guidelines should be understood as recommendations based on scientific knowledge and experience. They should be helpful in the dialogue with drug regulatory authorities. However they are not intended to represent any official requirements in this field.

\section{References}

1. FIP Guidelines for Dissolution Testing of Solid Oral Products (1981) Pharm Ind 43,334- 343

2. Pernarowski M (1974) Dissolution Methodology, in Leeson Lf and Carstensen $7 T$ (Eds.): Dissolution Technology. APhA, Washington, DC, 73

3. Krowczynski L (1978) Kritischer Vergleich von Geräten und Methoden zur Bestimmung der Auflösungsgeschwindigkeit von Tabletten. Pharmazie 33, $241-247$

4. Dakkuri A and Shak AC (1982) Dissolution Metbology: an Overview. Pbarm Technol 2, $41-53$

5. Latbia CD and Banakar WV (1986) Advances in Dissolution Technology: Design, pros and cons, Drug Dev Ind Pharm 12, 71 - 105

6. Siewert M (1991) Associations and Specifications, in Blume H, Grundert-Remy U, Möller H (Eds.): Controlled/Modified Release Products. Wissenschaftlicbe Verlagsgesellschaft, Stuttgart 7. Wells CE (1981) Effect of Sampling Probe Size on Dissolution of Tableted Drug Samples. 7 Pharm Sci 70, 232 - 233

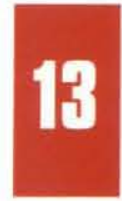


FIP... continued from previous page

8. Stricker H (1984) Optimierung und fustierung der Versucbsbedingungen von in vitro-Tests: Feste perorale Arzneizabereitungen. Acta Pbarm Tecbnol 30, $113-125$

9. Stricker H (1976) In-vitro-Studien zum Auflöse- und Resorptionsverbalten oral verabreichter Arzneistoffe und die Korrelation mit der biologischen Verf.gbarkeit. Pharm Ind 38, 232 - 234

10. Dibbern HW (1984) Verfigbarkeitsprififung in vitro: Forderungen, Möglichkeiten, Grenzen. Pbarm Ind 46,381 - 385

11. Das SK, Gupta BK (1988) Simulation of pbysiological pH-time profile in in vitro dissolution study: Relationship between dissolution rate and bioavailability of controlled release dosage form. Drug Dev Ind Pbarm 14, 537 - 544

12. Bhume H, Ali SL, Siewert M (1984) Zur pharmazeutiscben Qualität von glibenclanidbaltigen Fertigarzneimitteln. Pharm Ztg 129, 983 - 989

13. EEC Note for Guidance (1991) Quality of Prolonged Release Oral Solid Dosage Forms

14. Guidelines for Design and Evaluation of Oral Sustained Release Dosage Form (1988). Ministry of Health and Welfare of Japan. Yakuskin-1-5

15. Workshop Report (1990) In Vitro and In Vivo Testing and Correlation for Oral Controlled/Modified-Release Dosage Forms. Pharm Res 7, 975 - 982

16. Sbab VP, Konecny 77, Everett RL, McCullough B, Noorizadeh. AC, Skelly JP (1989) In Vitro Dissolution Profile of Water-Insoluble Drug Dosage Forms in the Presence of Surfactants. Pbarm Res 6 (7) 612 - 618

17. Sbah VP, Gurbarg M, Noory A, Dighe S, Skelly 7P (1991) Influence of Higher Rates of Agitation on Release Patterns of Immediate-Release Drug Products. F Pbarm Sci 81 (6) 500 - 503

18. $<1088>$ In-vitro and in-vivo evaluation of dosage forms (1995) USP 23

19. Qureshi SA and McGilveray If (1994) Impact of Different Deairation Methods on the USP Dissolution Apparatus Suitability Test Criteria, Pharm Forum 20 (6) 8565 - 8566

20. Soltero RA, Hoover 7M, Jones FT, Standish M (1989) Effects of Sinker Sbapes on Dissolution Profiles. 7 Pharm Sai 78, 35 - 39

21. U.S. Pbarmacopeia 23, Supplement 1 (1995): Drug Release <724> 2535

22. FIP Working Group: 4 Dissolution and Dissolution Specification. Apparatus Suitability Test for the Flow-tbrough Cell (publ. in prep.)

23. Langenbucher F (1982): Numerical convolution/deconvolution as a tool for correlating in vitro with in vivo drug availability. Pbarm. Ind., 44, 1166 - 1172

24. Langenbucher F (1982): Improved algorithms correlating body response with drug input, Pbarm. Ind., 44, 1275 - 1278.

25. Wagner 7W, Nelson F (1963): Percent absorbed time plots derived from blood level or urinary excretion data. 7. Pharm. Sci., 57, 918 - 928

26. Loo JCK, Riegelmann S (1968): New method for calculating the intrinsic absorption rate of drug 7. Pharm. Sci., 57, 918 - 928.

27. Brockmeier D, Voegele D, von Hattingberg HM (1983): In vitro-in vivo correlation, a time scaling problem? Arzneimittelforschung 33, 598 - 601

28. von Hattingberg HM (1984): Momenten-Analyse und in vitro/in vivo Korrelation, Acta Pharm. Tecbnol., 30, 93 - 101

29. Cardot 7M, Beysac E (1993): In vitro/in vivo Correlations: Scientific Implications and Standardisation. Eur 7 Drug Metab Pharmacokinet 18 (1) $113-120$

30. Siewert M (1994): In Vivo Validation of In Vitro Dissolution Tests and Specifications: Application for Controlled/Modified Release Products.

Biointernational 2 (293 - 299)

31. Oberle RL, Cben T-S, Lloyd C, Barnett 7L, C Owyang, Meyer 7. Amidon GL (1990): The influence of the interdigestive migrating motility complex on the gastric emptying of liquids. Gastroenterology $99,1275-1282$
32. Brener W, Hendrix TR, McHugh PR (1983): Regulation of the gastric emptying of glucose. Gastroenterology 85, $76-82$

33. Minamin H, McCallum R.W., (19984): The Physiology and Pbatophysiology of Gastric Emptying in Humams. Gastroenterology 86/6, 1592- 1610

34. Workshop Report (1993): Scale-Up of Immediate Release Oral Solid Dosage Forms. Pharm. Res. 10, 313 - 316 and Eur: 7. Pharm. Biopharm. $39(1), 40-43$

35. Workshop II Report (1993): Scale-Up of Oral Extended Release Dosage Forms. Pbarm. Res. 10, 1800 - 1805 and Eur. 7. Pharm. Biopharm. 39 (4), $162-167$

36. FDA Immediate Release Scale-up and Post Approval Change (SUPAC) Expert Working Group of the Cbemistry Mamufacturing Controls Coordinating Committee of the Center for Drug Evaluation and Research (1994) Interim Guidance Immediate Release Solid Oral Dosage Forms - Preand Post-Approval Changes.

37. Maturu PK, Prasad VK, Worsley W, Sbiu GK, Skelly 7P (1986) Influence of a bigh fat breakfast on the bioavailability of theophylline controlled-release formulations: an in vitro demonstration of an in vivo observation. In: 7. Pbarm. Sci. $75,1205-1206$

38. Wearly L, Karim A, Pagone F, Streicher 7, Wickman A (1988) Food-Induced Theophylline Release/Absorption Cbanges from Controlled-Release Formulations: A Proposed in Vitro Model. Drug Deol. Ind. Pharm. 14, 13 - 28

39. Karim A: Importance of Assessing Food Effects in Evaluating ControlledRelease Formulations. (1988) In: Yacobi A und Halperin-Walega E: Oral Sustained Release Formulations: Design and Evaluation. Pergamon Press, $157-181$

40. El-Arini K, Shiu GK, Skelly 7P (1990) Theophylline-Controlled Release Preparations and Fatty Food: An in vitro Study Using the Rotating Dialysis Cell. Pbarm. Res. 7, $1134-1140$

41. Macheras P, Koupparis M, Tsaprounis C (1986) Drug dissolution studies in milk using the automated flow injection serial dynamic dialysis technique. Int. 7. Pharm. 33, 125-136

42. Junginger HE, Verboeven 7, Peschier L7C (1990) Eine neues in vitro-Modell zur Erkennung von Wechselwirkungen zwischen Retardarzneimitteln zur oralen Applikation und Nabrungsmitteln. Pharm. Ztg. Wiss. 2, 53 - 58

43. Krömer 7, Lindauer RF, Siewert M, Stricker H, Bhume H (1993) ExtendedRelease Theophylline Alternative In Vitro Dissolution Methods. Eur: 7. Drug. Metab. Pharmacokin. 18, 37

44. Siewert M (1989): In vitro-Dissolution Testing of Oral Controlled Release Products. In: Gundert-Remy U und M ller H: Oral Controlled Release Products Therapeutic and Biopharmaceutic Assessment. Wissenschaftliche Verlagsgesellschaft, $139-154$

45. Galia E, Nicolaides E, Reppas C, Dressman 7B (1996): New media discriminate dissolution properties of poorly soluble drugs. Pharm. Researcb 13, 262

46. Ogata H et al, (1984): Development of and evaluation of a new peroral test agent GA-Test for assesment of gastric acidity. 7. Pharmacobio-Dyn 7, 656664

For Correspondence:

FIP Working Group 4: Dissolution and Dissolution Specifications

Dr. Martin Siewert

c10 Hoecbst Marion Roussel, Building K 607, D-65926 Frankfurt

This final "official" version of the FIP Guidelines for Dissolution Testing of Solid Oral Products will also be publisbed in International Pbarmacy,

Pharmacopoeial Forum, Die Pbarmazeutische Industrie and Pbarmaceutical Technology. 